\title{
Change in Body Fat during a Family-Based Treatment of Obesity in Children: The Relative Importance of Energy Intake and Physical Activity
}

\author{
Silje Steinsbekk ${ }^{a}$ b $\quad$ Lars Wichstrøm $^{a} \quad$ Rønnaug Ødegård ${ }^{c, d}$ \\ Ingar Mehus ${ }^{\mathrm{e}}$ \\ a Department of Psychology, Norwegian University of Science and Technology (NTNU), \\ ${ }^{b}$ Department of Child- and Adolescent Psychiatry, ${ }^{\mathrm{C}}$ Department of Pediatrics, St. \\ Olavs Hospital, dDepartment of Laboratory Medicine, Children's and Women's Health, \\ e Department of Sociology and Political Science, Norwegian University of Science and \\ Technology (NTNU), Trondheim, Norway
}

Key Words

Obesity $\cdot$ Child $\cdot$ Treatment $\cdot$ Energy intake $\cdot$ Physical activity

\begin{abstract}
Objective: The aim of the current study was to examine to what extent changes in reported energy intake and physical activity predict changes in body fat during a family-based outpatient treatment of obesity in children. Methods: Total body fat (DXA), reported energy intake (4-day diet record), and physical activity (accelerometer) was measured in 99 children (age 7-12 years, mean BMI SDS $=2.99$ ) at baseline as well as after 6 months 2 years of treatment. Repeated measures (GLM), growth modeling, and structural equation modeling (SEM) were applied in the data analyses. Results: There was significant decrease in body fat, reported energy intake, and physical activity at both follow-ups $(p<0.001)$ compared to baseline. Changes in reported energy intake from baseline to 6 months predicted a decrease in body fat from baseline to 6 months $(\beta=0.68, p<0.001)$. In addition, changes in reported energy intake had a strong indirect effect on body fat at 2-year follow-up, mediated by changes in body fat from baseline to 6 months (indirect $\beta=0.50, p<0.001$ ). Changes in physical activity did not predict changes in body fat during treatment. Conclusions: Changes in reported energy intake significantly affected body fat at 6 months and indirectly predicted the amount of body fat at 2-year follow-up. The indirect effect was mediated by a decrease in body fat obtained during the first phase of treatment.


Steinsbekk et al.: Change in Body Fat during a Family-Based Treatment of Obesity in Children: The Relative Importance of Energy Intake and Physical Activity

\section{Introduction}

Multi-dimensional interventions which include increased physical activity, reduced sedentary behavior, and the promotion of healthy eating are the most promising in the treatment of obesity in children [1]. It is assumed that decreased BMI or changes in body composition are caused by changes in physical activity and nutrition that are facilitated by the intervention in question. However, few studies have directly tested the relative merits of changes in physical activity and in reported energy intake during treatment in explaining altered body composition. One way of examining this is to compare the effectiveness of exercise only, diet only, and exercise plus diet programs. Studies have shown that diet and exercise, or diet alone, results in a significantly greater decrease in BMI z-scores compared to exercise-only interventions $[2,3]$. These studies suggest that diet might be the most important component in such programs. However, several links in the causal chain from behavioral interventions to weight loss need to be established before such a conclusion can be reached. First, since diet and physical activity are rarely controlled in these studies, change in one component could be compensated for by a change in the other component. Thus, although one review concluded that physical activity interventions in pediatric obesity generally achieved the aim of increasing physical activity [4], we do not know if the increased activity instigated increased reported energy intake as well. Therefore, one needs to document that the interventions actually had the intended effects on both diet and activity. One such study showed that a diet-only intervention had the intended effect on reduced caloric intake, but also that an exercise-only intervention led to a similar reduction in energy intake [5]. Second, one should be able to show, on an individual level, that the obtained changes in diet explains, i.e. mediates, the weight loss to a greater extent than increased physical activity - or vice versa. Decomposing the results from intervention studies by means of such mediation analyses will therefore add to our understanding of the effectiveness of treatment components [6]. Although the impact of pediatric weight loss interventions on physical activity and diet have been examined before [4, 5], mediational analyses have not been undertaken in treatment studies of pediatric obesity. Few studies have used mediation analysis to determine if changes in the hypothesized mediators were responsible for changes in the primary outcome of adult interventions as well [6]. However, there are two studies on internet-based interventions: In a study of weight loss in men, physical activity, portion size, total energy intake, alcohol intake, and fat intake were examined as possible mediators of weight change [6]. Interestingly, none of the specific mediators examined was significantly related to outcome, even though the study participants lost significant weight and their total reported energy intake decreased by approximately 3,000 kJ during the 6-month study period. Dietary change was also examined as a potential mediator in a family-based internet intervention for adolescent girls but could not explain the weight loss obtained [7].

The aim of the current study was hence for the first time to examine to what extent changes in reported energy intake and physical activity during a 2-year, family-based outpatient treatment of obesity in children could explain changes in body fat.

\section{Participants and Methods}

\section{Participants}

Participants were 99 children (48 girls, 51 boys) with a mean ( \pm SD) age of $10.3 \pm 1.7$ years and a mean BMI Standard Deviation Score (BMI SDS) of $2.99 \pm 0.46$. All but two of the children were ethnic Norwegians (Caucasian): one child was of African origin and the other of Latin-American origin. Measured 
Steinsbekk et al.: Change in Body Fat during a Family-Based Treatment of Obesity in Children: The Relative Importance of Energy Intake and Physical Activity

Table 1. Characteristics of the sample at baseline

\begin{tabular}{|c|c|}
\hline & Total $(\mathrm{N}=99)$ \\
\hline Mean age, years (SD) & $10.3(1.7)$ \\
\hline Mean weight, kg (SD) & $62.7(16.3)$ \\
\hline Mean height, cm (SD) & $146.8(11.3)$ \\
\hline Mean BMI, kg/m² (SD) & $28.60(4.1)$ \\
\hline Mean BMI SDS (SD) & $2.99(0.5)$ \\
\hline Mean \% body fat & $40.55(4.1)$ \\
\hline Mean mother's BMI $(\mathrm{N}=91), \mathrm{kg} / \mathrm{m}^{2}(\mathrm{SD})$ & $31.86(7.3)$ \\
\hline Mean father's BMI $(\mathrm{N}=48), \mathrm{kg} / \mathrm{m}^{2}(\mathrm{SD})$ & $29.88(3.6)$ \\
\hline \multicolumn{2}{|l|}{ Parents' occupation* $\%$} \\
\hline Unskilled workers & 5.2 \\
\hline Farmers/fishermen & 3.1 \\
\hline Skilled workers & 47.4 \\
\hline Lower professionals & 22.7 \\
\hline Higher professionals & 11.3 \\
\hline Leaders & 10.3 \\
\hline \multicolumn{2}{|l|}{ The child's caregiving situation, \% } \\
\hline Living with both parents & 60.2 \\
\hline Living with a single parent & 16.3 \\
\hline Single parent and her/his new partner & 16.3 \\
\hline Half time with each parent & 5.1 \\
\hline Foster parents & 2.0 \\
\hline
\end{tabular}

*Classification of parents' occupation is based on the International Standard of Classification of Occupations (ISCO-88).

height and weight records for the children's parents showed that their fathers $(\mathrm{N}=54)$ had a mean BMI of $29.9 \pm 3.6 \mathrm{~kg} / \mathrm{m}^{2}$ and their mothers ( $\mathrm{N}=91$ ) a mean BMI of $31.9 \pm 7.3 \mathrm{~kg} / \mathrm{m}^{2}$ at baseline. Baseline characteristics are presented in table 1.

\section{Procedure}

Children referred to outpatient obesity treatment at St. Olav Hospital, the general hospital in Trondheim, Norway, between April 2005 and February 2008, were recruited after meeting the following three inclusion criteria: a BMI SDS $\geq 2$ [8]; the participation of at least one parent; and the ability to participate in a group setting. $80 \%$ of those who met the inclusion criteria joined the treatment program, resulting in a study population of 99 children (48 girls and 51 boys). The majority of the remaining $20 \%$ of the children initially referred withdrew because they did not want treatment after all. Body composition data was missing for two of the children at baseline. Of the 99 participants, 2 dropped out after pre-treatment assessment, and 8 dropped out during the first 6-month treatment period, yielding a 6-month follow-up sample of 89 children. Nine additional children dropped out between the 6-month and 2-year follow-up. Reasons given for the drop-outs were as follows: an inability to continue to participate in the treatment program because of a family situation ( $\mathrm{n}=8)$; a lack of motivation for treatment $(n=1)$; no further need of treatment $(n=1)$; and inability to continue to participate in the treatment program because the family moved away $(n=2)$. Seven families did not report a reason for dropping out.

Data was collected in a hospital setting by the members of the treatment staff, before onset of treatment, after 6 months, and after 2 years of treatment. Body fat was measured by trained personnel not involved in the treatment. Written informed consent was obtained from all parents, and the study was approved by the Regional Ethical Committee for Medical Research. The treatment program was not advertised, and no payment was required for participation. 


\section{Treatment Program}

The treatment program aimed to increase the families' daily level of physical activity, reduce their sedentary behavior, and establish healthy dietary habits with proper nutrition for the entire family. Based on international and national recommendations $[9,10]$, the intervention focused on regular mealtimes, increased intake of fruits and vegetables, less sugar and fat, more fiber-dense food, at least $1 \mathrm{~h}$ of moderate physical activity per day, and reduced sedentary behavior. Daily physical activity involved walking instead of riding in a car, taking the stairs rather than using an elevator, playing outside, bicycling, and general exercising. The intervention aims were accomplished by arranging for the children to have positive experiences with physical activity and to increase the nutritional knowledge of both parents and children. In addition, the program was designed to strengthen the parents' competence and skills required to accomplish the necessary lifestyle changes. Behavioral change techniques, such as monitoring, goal-setting, modeling, self-talk and reward, were applied. The treatment was family-based and took place in an outpatient hospital setting, where parents participated in a parent group and children participated in age-specific child groups. In the group sessions, the children participated in different activities such as climbing, ball games and swimming as well as education and tasks related to healthy eating. All groups met every 2 nd week for 10 2-hour sessions during the first 6 -month treatment period. In addition, each family met once a month with a physiotherapist and a clinical dietician for individual consultations (30 min) in order to discuss the family's lifestyle changes and define new goals. Over the remaining 18 months of the 2-year intervention program, the groups met 5 times at the hospital.

\section{Measures}

\section{Anthropometry and Body Composition}

Anthropometry was measured with the children wearing light clothing and no shoes. Weight was obtained using a digital scale (Seca 930; Vogel \& Halke, Hamburg, Germany) and height was measured using a stadiometer (Hyssna Limfog AB, Strömkulla, Sweden). BMI was calculated in $\mathrm{kg} / \mathrm{m}^{2}$ and BMI SDS was computed. Due to lack of Norwegian norms at the initialization of the current treatment study, British reference values were applied [11, 12]. Dual energy X-ray absorptiometry (DXA) (Discovery QDR; Holologic, Huddinge, Sweden), which is one of the most accurate methods to measure body composition [13], was used to estimate $\%$ total body fat.

\section{Energy Intake}

A 4-day food record was used to estimate each child's reported energy intake. This food record covered 3 consecutive weekdays and 1 weekend day, beginning on either a Wednesday or a Sunday. The parents received the dietary record forms by post, and it was not specified whether the parents or the child should be responsible for the food intake registration. They were instructed to register everything the child ate and drank during the 4-day food record period. Recording food intake both at each meal and between meals was emphasized in the written material the families were given along with the food record forms. To improve the participants' accuracy in reporting portion sizes, an evaluated photographic booklet with a photograph series of 13 food items of known portion size was used [14]. Foods could also be compared to household measures or the standard weights of food items. Before calculating food intake, a clinical dietitian met with the family to clarify details about the food record in order to make the record as accurate as possible. Total caloric intake (kcal) was calculated by a clinical dietitian using 'Food on the Internet' version 5.1., a web-based dietary analysis program based on the Norwegian Food Composition Table 2006 (MVT-06) [15]. A 4-day food record was conducted at baseline, after 6 months and at the end of 2 years of treatment.

\section{Physical Activity}

Physical activity was measured using an Actigraph GT1M accelerometer (ActiGraph LLC, Pensacola, FL, USA) worn around the waist. Children were instructed to wear the monitor for 7 consecutive days, except when they were sleeping, swimming, and showering or bathing. Activity data were recorded in 1-min epochs and processed using accelerometer analysis software (MAHUffe) [16]. In the current study, 
analyses were carried out using general physical activity (GPA), reported in mean counts/min. GPA appears to be a robust parameter that is not affected by epoch length and can be compared between studies [17]. Only data from children who had registered activity data for at least $480 \mathrm{~min}$ a day, for at least 3 days were included in the study. These criteria are comparable to those used in other studies [18]. 80, 56 and 54 children fulfilled these criteria at baseline, at the 6-month assessment and at the 2-year assessment, respectively.

\section{Statistical Analysis}

Repeated measures (general linear models), using PASW 17.0, were applied to analyze changes in total body fat, reported energy intake, and physical activity at baseline, at 6 months, and at the end of the 2 years of treatment. Growth modeling, a technique for modeling within-person change across repeated measures and between-person differences in those changes [19], was used to capture individual differences in change during treatment. In order to enable growth analysis using only two observation points, residuals were fixed to zero. Thus, growth factors were treated as observed variables. Growth analysis yields two factors. The first is the intercept, which was defined in the present study as the growth starting point. Because we used only two measurement points in the growth analysis, the intercept is identical to the baseline value. The second factor is the slope, which represents the change from baseline to 6 months in the current study. Grow th factors were calculated using a Bayesian estimation [20]. In Bayesian analysis, modeling with missing data gives asymptotically the same results as maximum-likelihood estimation [21]; thus information from all 99 subjects were used to estimate the coefficients.

Structural equation modeling (SEM) was used to examine both the relationship between the growth factors and the relationship between the growth factors and total body fat at the end of treatment. In our model we hypothesized, on biological grounds, that changes in reported energy intake and energy expenditure (i.e. activity level) cause changes in body fat during the treatment period, and not vice versa. All intercepts were allowed to correlate, whereas all slopes were regressed on all intercepts. Finally, body fat at 2 years was regressed on all intercepts and slopes. Both growth modeling and SEM was conducted using Mplus Version 6.0 [21]. Posterior Predictive Model Checking (PPMC) was used to evaluate the goodness of fit of the overall model. PPCM is based on the rationale that, if a model fits the data, the observed data should look like replicated data generated from the posterior distribution of the model parameters [22]. Differences between the observed and generated data in discrepancy measures incorporated in PPMC are evaluated by the Posterior Predictive P (PPP) value [22]. PPP values near 0.5 indicate that a realized discrepancy measure value looks similar to the posterior predictive values, indicating the goodness of fit of the model, whereas PPP values near 0 or 1 indicate misfit [22]. A 95\% confidence interval (95\% CI) was applied. To test the statistical significance of mediation, Sobel's Test was used [23].

The size of the sample in the current study was equal to the number of patients receiving obesity treatment for a certain period of time, and therefore was not based on prospective power analysis. The current sample size enabled us to detect standardized beta weights of 0.28 , in multiple regressions with a power of 0.80 .

\section{Results}

There was a significant decrease in body fat, reported energy intake, and physical activity from baseline to 6 months and 2 years of treatment, as can be seen in table 2 .

As shown in table 3, the slope of body fat, viz. change in body fat, was significantly predicted by the slope of reported energy intake, but not by the slope of physical activity. In addition, the intercept of body fat, viz. body fat at intake, was significantly correlated with the intercept of reported energy intake $(r=0.37,95 \% \mathrm{CI}=0.17-0.53, \mathrm{p}<0.001)$, but not with the intercept of the physical activity variable $(r=0.13,95 \% \mathrm{CI}=-.0 .08$ to.0.30, $\mathrm{p}=0.16)$. This trend was also evident in analyses of the 2-year follow-up data (table 4).

Although the change in reported energy intake observed from baseline to 6 months (i.e. the slope of reported energy intake) did not directly predict the body fat measured at the 2-year follow-up, there was a strong indirect effect, mediated by the decreased body fat observed from baseline to 6 months (the slope of body fat) (indirect $\beta$ : $0.68 \times 0.74=0.50$, 
Table 2. Total body fat, reported energy intake and physical activity during treatment. Repeated measures

\begin{tabular}{|c|c|c|c|c|c|c|c|c|c|}
\hline & \multirow{2}{*}{$\begin{array}{l}\text { Baseline }(n=97) \text {, } \\
\text { mean }(S D)\end{array}$} & \multirow{2}{*}{$\begin{array}{l}6 \text { months }(n=89) \text {, } \\
\text { mean }(S D)\end{array}$} & \multirow{2}{*}{$\begin{array}{l}2 \text { years }(n=80) \text {, } \\
\text { mean }(S D)\end{array}$} & \multicolumn{3}{|c|}{ Baseline -6 months } & \multicolumn{3}{|c|}{ Baseline - 2 years } \\
\hline & & & & $\mathrm{df} F$ & $p$ & $d^{*}$ & $\mathrm{df} F$ & $p$ & $d^{*}$ \\
\hline$\%$ body fat & $40.54(4.08)$ & $38.33(4.94)$ & 38.50 (5.59) & 164.33 & 0.00 & 0.49 & 117.83 & 0.00 & 0.42 \\
\hline $\begin{array}{c}\text { Reported energy } \\
\text { intake, kcal }\end{array}$ & $1,771.51(381.25)$ & $1,572.17(346.03)$ & $1,601.43(322.93)$ & 119.10 & 0.00 & 0.55 & 122.66 & 0.00 & 0.48 \\
\hline $\begin{array}{l}\text { Physical activity, } \\
\text { Cmin }\end{array}$ & $670.73(278.45)$ & $517.71(147.17)$ & $486.14(152.73)$ & 115.93 & 0.00 & 0.69 & 125.10 & 0.00 & 0.82 \\
\hline
\end{tabular}

${ }^{*}$ Cohen`s d was used to estimate effect size.

Table 3. Path model: changes in body fat, reported energy intake and physical activity from baseline to 6 months regressed on intercepts and slopes of body fat, reported energy intake, and physical activity ${ }^{a}$

\begin{tabular}{|c|c|c|c|}
\hline \multirow[t]{2}{*}{ Predictors } & \multicolumn{3}{|c|}{ Outcomes: slopes - changes from baseline to 6 months } \\
\hline & body fat & reported energy intake & physical activity \\
\hline \multicolumn{4}{|l|}{ Body fat } \\
\hline Intercept & $-0.36^{* * *}$ & NM & NM \\
\hline Slope & NA & NM & NM \\
\hline \multicolumn{4}{|c|}{ Reported energy intake } \\
\hline Intercept & $0.53^{* * *}$ & $-0.57^{* * *}$ & $0.24^{* * *}$ \\
\hline Slope & $0.68^{* * *}$ & NA & NM \\
\hline \multicolumn{4}{|c|}{ Physical activity } \\
\hline Intercept & 0.16 & $-0.24^{* * *}$ & $-0.76^{* * *}$ \\
\hline Slope & -0.05 & NM & NA \\
\hline
\end{tabular}

Table 4. Path model: body fat, reported energy intake and physical activity at 2 years follow-up regressed on intercepts and slopes of body fat, reported energy intake, and physical activity ${ }^{\mathrm{a}}$

\begin{tabular}{|c|c|c|c|}
\hline \multirow[t]{2}{*}{ Predictors } & \multicolumn{3}{|c|}{ Outcomes: status at 2 years follow-up } \\
\hline & body fat & reported energy intake & physical activity \\
\hline \multicolumn{4}{|l|}{ Body fat } \\
\hline Intercept & $0.46^{* * *}$ & $-0.32^{* *}$ & 0.09 \\
\hline Slope & $0.74^{* * *}$ & $0.64^{* * *}$ & -0.23 \\
\hline \multicolumn{4}{|c|}{ Reported energy intake } \\
\hline Intercept & $-0.37^{* *}$ & $0.59^{* * *}$ & 0.02 \\
\hline Slope & -0.27 & 0.36 & 0.06 \\
\hline \multicolumn{4}{|c|}{ Physical activity } \\
\hline Intercept & -0.12 & 0.18 & $0.62^{* *}$ \\
\hline Slope & 0.09 & 0.08 & $0.54^{* *}$ \\
\hline
\end{tabular}


$\mathrm{p}<0.001$, see table 4). As expected, both the intercept and the slope of body fat significantly predicted body fat at end of treatment. With respect to physical activity, in contrast, there was neither a direct nor an indirect effect of the growth factors on body fat at the end of treatment. However, the results did show that the slope of physical activity significantly predicted comparatively higher levels of physical activity at 2 years of treatment. Furthermore, as can be seen in table 4, there was a negative relationship between reported energy intake at baseline and body fat measured at the 2-year follow-up. In addition, reported energy intake at 2 years was strongly predicted by baseline-reported energy intake levels. Overall, our model fitted well with the data, PPP $=0.46$ (PPMC $=-19.42$ to 33.50).

\section{Discussion}

The main purpose of the current study was to examine how changes in physical activity and diet predict changes in body fat during an outpatient, family-based treatment of obesity in children. There was a significant decrease in total body fat, reported energy intake, and physical activity both at 6 months and at the end of 2 years of treatment. The results showed that the decrease in body fat observed after 6 months of treatment could be explained by changes in reported energy intake, but not by changes in physical activity over the same period. In addition, there was a strong indirect effect of altered energy intake on body fat at the 2-year follow-up, which was mediated by changes in body fat from baseline to 6 months. This indicates that the dietary changes made in the first 6 months of treatment had a sustained effect on body fat at 2 years. However, body fat was neither directly nor indirectly affected by changes in physical activity at the end of treatment. Physical activity was also unrelated to body fat at baseline, whereas reported energy intake was correlated with body fat.

The decrease obtained in body fat and reported energy intake from baseline to the end of treatment is comparable with those of other studies [5, 24]. However, the use of mediation analysis to identify the possible mechanisms through which the intervention achieves its effects is novel in family-based treatment of obesity. Although pediatric obesity interventions have been shown to affect energy intake, the current study expands this knowledge by statistically testing whether changes in reported energy intake were actually responsible for changes in body fat. We found that reduced reported energy intake predicted a decrease in body fat. A study of a school-based obesity prevention program showed similar findings; the effect of the implemented intervention on BMI was mediated by the changes in fruit, fat and oil intakes, but physical activity was not a significant mediator [25]. Further, adult obesity studies report that most weight loss occurred as a result of decreased reported energy intake [26]

In agreement with the current results, studies have shown that the rate of weight loss decreases over time and that changes during the first phase of treatment predict changes at the end of treatment [27]. The fact that changes in reported energy intake during the first 6 months of treatment indirectly predict body fat at 2 years of treatment indicates that, even though the direct effect of the changes are only short-term, they are influential in sustaining a decrease, or at least in reducing a potential increase, in body fat at the 2-year follow up. From a clinical standpoint, it is reasonable to assume that children who are able to change their diet significantly during the first phase of treatment will have the largest body fat decreases, and even though the children's reported energy intake does not decrease any further, the effect of the changes will be sustained. As our results show, there is no significant relationship between changes in reported energy intake from baseline to 6 months 
and reported energy intake at the end of treatment. In addition, our findings suggest that those children who reduce their reported energy intake the most during the first 6 months of treatment are not necessarily those who have the relatively lowest reported energy intake at the end of treatment.

The lack of a direct relationship between reported energy intake changes from baseline to 6 months and body fat at 2 years may be related to the time and intensity of the treatment. During the first 6 months of treatment, the families met at the hospital twice a month for 10 sessions, whereas for the rest of the treatment period, only 5 booster sessions were arranged. The effect of weight loss interventions declines over time [27], and higher intensity of the intervention predict better outcomes [28]. Furthermore, in the current study high reported energy intake at baseline predicted lower body fat at 2-year follow-up. One possible explanation is that children with a very high reported energy intake at baseline have the greatest potential to decrease their reported energy intake and, therefore, reduce their body fat the most through treatment. One may suspect that overweight children with a comparatively low reported energy intake at baseline may already have made changes to their diets prior to treatment. Such 'early starters' may be more inclined to revert back to a higher energy intake because this low baseline intake is difficult to maintain through treatment. As a result low reported energy intake at the beginning of treatment may be predictive of higher body fat at the end of treatment.

In the current study, changes in physical activity were unrelated to body fat at baseline, during treatment, and at end of treatment. Contrary to the aims of the intervention, physical activity was reduced from start to the end of treatment. The fact that there was a decrease at the group level is immaterial to explanation of individual differences. The lack of association between changes in physical activity and later adiposity imply that those who became more physically active did not become less obese compared to those who reduced their physical activity. The variability in mean scores and in changes indicates that there were indeed children who increased their physical activity, at least compared to the others, even though the intervention was not successful in altering the mean level of physical activity. One would thus still expect those children who did increase their physical activity to attain comparatively reduced body fat. One possible explanation for the lacking effect might be that the changes made in energy expenditure were not large enough to translate into detectable changes in energy reserve, i.e. body fat, given the current sample size. The main aim of the physical activity component of the current intervention was to increase daily life physical activity, and supervised exercise was not included as part of the treatment. It has been shown that physical activity, in order to affect body fat in overweight individuals, has to be of high intensity [29], which possibly explains the current results. This decrease in activity is in contrast to a comparable study of Scottish children with obesity, where physical activity measured increased during treatment [30]. One reasonable conclusion is that the physical activity component of the current intervention was ineffective. However, the decrease in the mean level of physical activity during the 2-year intervention may also be related to a general decline in physical activity during the adolescent years [31]. The lack of a control group makes it difficult to conclude whether the decline is less than would be expected, but it is comparable to the decline in the level of physical activity found in Norwegian 8- to 15-year-olds [32]. In addition, the obese children of the current study had baseline levels of physical activity comparable to that found in the general population of children. This is contrary to earlier findings showing that overweight and obese children are less physically active than their normal-weight peers [33, 34]. Starting out with a relatively high baseline level of physical activity, it might be more challenging to achieve an increase and more likely to get a decrease in the level of physical activity. The decline in activity from baseline to 6 months might further be related to 
seasonal differences in physical activity. Riddoch et al. [35] found a summer-winter difference of 108 counts/min in 11-year-old children. In the current study, baseline data was collected from April to May, and 6-month data was collected from October to November. However, the positive relationship between changes in physical activity and the level of physical activity at 2 years indicates that those who comparatively changed their level of activity the most at the beginning of the study were those who were the most physically active at end of treatment, suggesting some stabilization of physical activity levels during the 2 years of treatment.

The present findings should be interpreted in the context of some strengths and limitations. Obesity is due to excessive body fat, and the use of body fat as an outcome measure is therefore an advantage of the current study. Using body fat rather than BMI as an outcome measure is especially important when addressing both physical activity and diet, because of the possibility that a rise in lean mass will mask a decrease in body fat [36]. DXA is widely used and has the benefit of accurately quantifying body fat [13]. The use of an accelerometer to objectively measure physical activity further strengthens the findings, and the outcomes used in the current study (counts/min) have been shown to have good validity and reliability [37]. Furthermore, the dietary assessment in the current study was based on a dietary food record rather than dietary recall. Even though dietary intake cannot be estimated without error, the use of prospective methods of assessment has the advantage of not relying on memory [38], thereby increasing accuracy. Nevertheless, validation studies of energy intake data indicate that much of the dietary data from children and adolescents is prone to reporting error, mostly through underreporting [39]. In addition, higher weight individuals tend to underreport energy intake to a greater degree [40]. In order to increase the accuracy of the reported portion sizes, an evaluated photographic booklet was used in the current study [14]. Another limitation of the dietary assessment is the lack of a specific instruction in regard to who should be responsible for the food intake registration. We can therefore not be sure whether the child or the parent completed the records. Further, since the children aged 2 years between the first and the last registration, it might well be that parents registered food intake at baseline, whereas the child was responsible for registration at the end of treatment. This may represent a random error.

Another possible measurement limitation of the current study is that data was collected by the treatment staff. However, body composition, the main treatment outcome, was measured by staff not involved in the intervention, and is therefore not prone to bias. In addition, the use of an accelerometer and the food record method imply that treatment staff were only involved in study logistics (i.e. distribution of accelerometers) and technical handling (i.e. food calculations) of the data, but not in the data collection itself. Another limitation of the present study is the assumption that changes in reported energy intake and physical activity during treatment predict changes in body fat during treatment, not vice versa. This assumption is reasonable based on biological reasons, but, hypothetically, changes in weight may also predict changes in reported energy intake and activity for psychological reasons. If a person experiences weight gain, he/she (or the parents) might instigate a reduction of reported energy intake, and increase the level of physical activity in order to reverse the increase in body fat.

A strength of the present study is the representativeness of the sample; which included nearly all of the children referred to outpatient obesity treatment at the hospital over several years, and the drop-out rate was relatively small compared to other studies [41]. It should be noted though that the sample differs from Norwegian official statistics in regard to parents' occupation and children's caregiving situation. This difference is probably due to the fact that national numbers include the whole workforce ranging from age 18 years, and the clinical sample contains a selective group of adults, namely parents of children aged 
7-12 years. In addition, childhood obesity is associated with low socioeconomic status (SES) $[42,43]$. We can therefore not expect the sample of the current study to be representative for the Norwegian population in regard to SES. With regard to the low drop-out rate, parent reports of confidence in doing well in treatment have shown to predict treatment completion in addition to early treatment response [44]. It might be that the relatively intensive treatment during the first 6 months of the current intervention and the high level of parental involvement strengthened parental confidence and facilitated early treatment response. Having no alternative treatment options might also explain the relatively low drop-out rate.

\section{Conclusions}

In summary, changes in children's reported energy intake when engaged in obesity treatment significantly reduced their body fat in the short term and indirectly over a 2-year span. The obtained changes in physical activity, however, did not affect body fat. The finding that changes in reported energy intake, but not changes in physical activity, can predict body fat reduction expands our knowledge about the relative importance of the different components of pediatric obesity interventions. This appears to be the first study using mediation analysis to examine the relationship between diet, physical activity, and body fat during obesity treatment in children, and the results are therefore in need of replication.

\section{Acknowledgements}

This work was supported by the Liaison Committee for Central Norway Regional Health Authority; the National Council of Mental Health/Health and Rehabilitation, NTNU; and St. Olavs University Hospital.

\section{Disclosure Statement}

No conflict of interest is declared.

\section{References}

1 Oude Luttikhuis H, Baur L, Jansen H, Shrewsbury VA, O'Malley C, Stolk RP, Summerbell CD: Interventions for treating obesity in children. Cochrane Database Syst Rev. 2009:CD001872.

2 Shalitin S, Ashkenazi-Hoffnung L, Yackobovitch-Gavan M, Nagelberg N, Karni Y, Hershkovitz E, Loewenthal N, Shtaif B, Gat-Yablonski G, Phillip M: Effects of a twelve-week randomized intervention of exercise and/ or diet on weight loss and weight maintenance, and other metabolic parameters in obese preadolescent children. Horm Res 2009;72:287-301.

3 Yackobovitch-Gavan M, Nagelberg N, Phillip M, Ashkenazi-Hoffnung L, Hershkovitz E, Shalitin S: The influence of diet and/or exercise and parental compliance on health-related quality of life in obese children. Nutr Res 2009;29:397-404.

- 4 Cliff DP, Okely AD, Morgan PJ, Jones RA, Steele JR: The impact of child and adolescent obesity treatment interventions on physical activity: A systematic review. Obes Rev 2010;11:516-530.

- 5 Burrows T, Warren JM, Baur LA, Collins CE: Impact of a child obesity intervention on dietary intake and behaviors. Int J Obes 2008;32:1481-1488.

- 6 Lubans DR, Morgan PJ, Collins CE, Warren JM, Callister R: Exploring the mechanisms of weight loss in the shed-it intervention for overweight men: A mediation analysis. Int J Behav Nutr Phys Act 2009;6:76.

7 White MA, Martin PD, Newton RL, Walden HM, York-Crowe EE, Gordon ST, Ryan DH, Williamson DA: Mediators of weight loss in a family-based intervention presented over the internet. Obes Res 2004;12:10501059. 
Steinsbekk et al.: Change in Body Fat during a Family-Based Treatment of Obesity in

Children: The Relative Importance of Energy Intake and Physical Activity

- 8 Cole TJ, Bellizzi MC, Flegal KM, Dietz WH: Establishing a standard definition for child overweight and obesity worldwide: International survey. Br Med J 2000;320:1240-1243.

9 Norwegian Directory of Health: Norwegian Recommendations for Nutrition and Physical Activity. Oslo, 2005, 2011.

10 Barlow SE: Expert committee recommendations regarding the prevention, assessment, and treatment of child and adolescent overweight and obesity: summary report. Pediatrics 2007;120:164-192.

11 Cole TJ, Freeman JV, Preece MA: Body-mass index reference curves for the UK, 1990. Arch Dis Child 1995; 73:25-29.

$\$ 12$ Cole TJ, Freeman JV, Preece MA: British 1990 growth reference centiles for weight, height, body mass index and head circumference fitted by maximum penalized likelihood. Stat Med 1998;17:407-429.

13 Helba M, Binkovitz LA: Pediatric body composition analysis with dual-energy x-ray absorptiometry. Pediatr Radiol 2009;39:647-656.

14 Lillegaard ITL, Overby NC, Andersen LF: Can children and adolescents use photographs of food to estimate portion sizes? Eur J Clin Nutr 2005;59:611-617.

15 Food Safety Authority, the Directorate for Health, the Department of Nutrition at the University of Oslo: Norwegian Food Composition Table, 2006, 2011.

16 MRC Epidemiology Unit: www.mrc-epid.cam.ac.uk//Resarch/Publications.

17 Dencker M, Andersen LB: Health-related aspects of objectively measured daily physical activity in children. Clin Physiol Funct Imaging 2008;28:133-144.

18 Riddoch CJ, Andersen LB, Wedderkopp N, Harro M, Klasson-Heggebo L, Sardinha LB, Cooper AR, Ekelund U: Physical activity levels and patterns of 9-and 15-yr-old european children. Med Sci Sports Exerc 2004; 36:86-92.

19 Grimm KJ, Ram N: Nonlinear growth models in Mplus and SAS. Struct Equ Modeling 2009;16:676-701.

20 Muthen B, Asparouhov T: Bayesian SEM: a more flexible representation of substantive theory. www.statmodel.com/download/BSEMv4.pdf..

21 Muthèn LK, Muthèn BO: Mplus User's Guide. 6th ed. Los Angeles, Muthen \& Muthen, 2010.

22 Zhu X: Assessing Fit of Item Response Models for Performance Assessments using Bayesian Analysis: School of Education. PhD thesis, Pittsburgh, University of Pittsburgh, 2009, pp 304.

23 Sobel ME: Asymptotic confidence intervals for indirect effects in structural equation models; in Leinhardt S (ed): Sociological Methodology. Washington DC, American Sociological Association, 1982, pp 290-312.

24 Reinehr T, Schaefer A, Winkel K, Finne E, Toschke AM, Kolip P: An effective lifestyle intervention in overweight children: findings from a randomized controlled trial on 'obeldicks light'. Clin Nutr 2010;29:331336.

25 Angelopoulos PD, Milionis HJ, Grammatikaki E, Moschonis G, Manios Y: Changes in BMI and blood pressure after a school based intervention: the children study. Eur J Pub Health 2009;19:319-325.

26 National Institutes of Health NH, Lung, and Blood: The Practical Guide: Identification, Evaluation, and Treatment of Overweight and Obesity in Adults. Washington, DC, National Heart, Lung, and Blood Institute, 2000.

27 Reinehr T, Temmesfeld M, Kersting M, De Sousa G, Toschke AM: Four-year follow-up of children and adolescents participating in an obesity intervention program. Int J Obes 2007;31:1074-1077.

28 Whitlock EP, O'Connor EA, Williams SB, Beil TL, Lutz KW: Effectiveness of weight management interventions in children: a targeted systematic review for the USPSTF. Pediatrics 2010;125:E396-E418.

29 Ness AR, Leary SD, Mattocks C, Blair SN, Reilly JJ, Wells J, Ingle S, Tilling K, Smith GD, Riddoch C: Objectively measured physical activity and fat mass in a large cohort of children. Plos Med 2007;4:476-484.

-30 Hughes AR, Stewart L, Chapple J, McColl JH, Donaldson MDC, Kelnar CJH, Zabihollah M, Ahmed F, Reilly JJ: Randomized, controlled trial of a best-practice individualized behavioral program for treatment of childhood overweight: Scottish Childhood Overweight Treatment Trial (SCOTT). Pediatrics 2008; 121:E539-E546.

31 Armstrong N, Welsman JR: The physical activity patterns of European youth with reference to methods of assessment. Sports Med 2006;36:1067-1086.

32 Helsedirektoratet: Fysisk aktivitet blant barn og unge i norge. En kartlegging av aktivitetsnivå og fysisk form hos 9- og 15 åringer. Oslo, Helsedirektoratet, 2008.

-33 Ekelund U, Sardinha LB, Anderssen SA, Harro M, Franks PW, Brage S, Cooper AR, Andersen LB, Riddoch C, Froberg K: Associations between objectively assessed physical activity and indicators of body fatness in 9- to 10-y-old European children: a population-based study from 4 distinct regions in Europe (the European Youth Heart Study). Am J Clin Nutr 2004;80:584-590.

34 Page A: Physical activity patterns in nonobese and obese children assessed using minute-by-minute accelerometry. Int J Obes 2005;29:1070-1076.

-35 Riddoch CJ, Mattocks C, Deere K, Saunders J, Kirkby J, Tilling K, Leary SD, Blair SN, Ness AR: Objective measurement of levels and patterns of physical activity. Arch Dis Child 2007;92:963-969.

-36 Sacher PM, Kolotourou M, Chadwick PM, Cole TJ, Lawson MS, Lucas A, Singhal A: Randomized controlled trial of the mend program: a family-based community intervention for childhood obesity. Obesity 2010; 18(suppl 1):S62-S68.

37 Trost SG: Objective measurement of physical activity in youth: current issues, future directions. Exerc Sport Sci Rev 2001;29:32-36. 
-38 Collins CE, Watson J, Burrows T: Measuring dietary intake in children and adolescents in the context of overweight and obesity. Int J Obes 2010;34:1103-1115.

-39 Livingstone MBE, Robson PJ, Wallace JMW: Issues in dietary intake assessment of children and adolescents. Br J Nutr 2004;92(suppl 2):S213-S222.

40 Fisher JO, Johnson RK, Lindquist C, Birch LL, Goran MI: Influence of body composition on the accuracy of reported energy intake in children. Obes Res 2000;8:597-603.

41 Karlson CW, Rapoff MA: Attrition in randomized controlled trials for pediatric chronic conditions. J Pediatr Psychol 2009;34:782-793.

-42 Shrewsbury V, Wardle J: Socioeconomic status and adiposity in childhood: a systematic review of crosssectional studies 1990-2005. Obesity 2008;16:275-284.

43 Juliusson PB, Eide GE, Roelants M, Waaler PE, Hauspie R, Bjerknes R: Overweight and obesity in Norwegian children: prevalence and socio-demographic risk factors. Acta Paediatr 2010;99:900-905.

44 Gunnarsdottir T, Njardvik U, Olafsdottir AS, Craighead LW, Bjarnason R: The role of parental motivation in family-based treatment for childhood obesity. Obesity 2011;19:1654-1662. 